\title{
Fluorinated Biphenyldicarboxylate-based Metal-Organic Framework Exhibiting Efficient Propyne/Propylene Separation
}

Zhao-Ting Lin, ${ }^{\dagger}$ Qing-Yan Liu, ${ }^{*, \dagger}$ Ling Yang, ${ }^{\ddagger}$ Chun-Ting He, ${ }^{\dagger}$ Libo Li, ${ }^{\ddagger}$ and Yu-Ling Wang, ${ }^{*}{ }^{\dagger}$

${ }^{\dagger}$ College of Chemistry and Chemical Engineering, Jiangxi Normal University, Nanchang 330022, China.

"Shanxi Key Laboratory of Gas Energy Efficient and Clean Utilization, College of Chemistry and Chemical Engineering, Taiyuan University of Technology, Taiyuan 030024, Shanxi, China.

\section{Supporting Information}

\section{Experimental Section}

Chemicals. All chemicals were obtained commercially except for 3,3',5,5'-tetrakis(fluoro)biphenyl $-4,4^{\prime}$-dicarboxylic acid, which was prepared as schemed following.

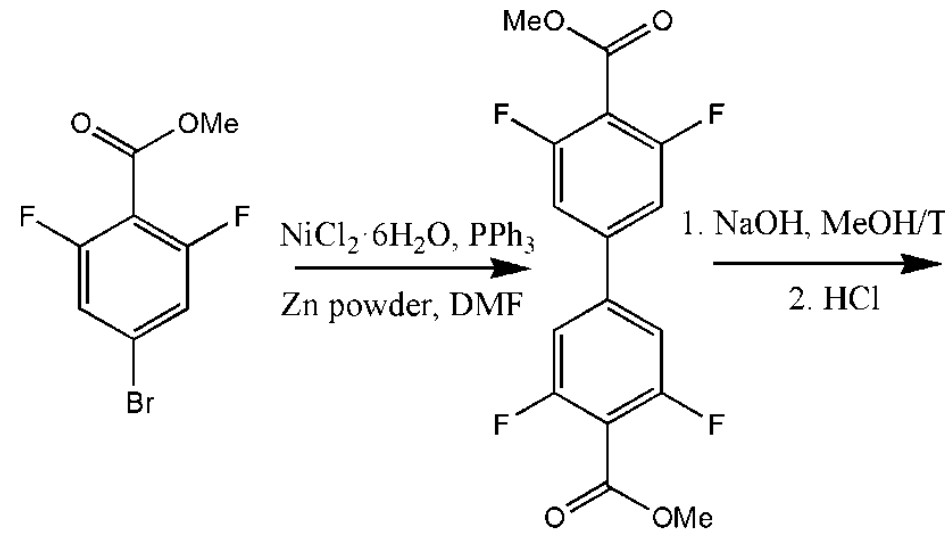

(a)<smiles>O=C(O)c1c(F)cc(-c2cc(F)c(C(=O)O)c(F)c2)cc1F</smiles>

(b)

Scheme S1 Synthesis of 3,3',5,5'-tetrakis(fluoro)biphenyl -4,4'-dicarboxylic acid.

(1) Synthesis of dimethyl 3,3',5',-tetrakis(fluoro)biphenyl-4,4'-dicarboxylate (a).The reaction was carried out under a $\mathrm{N}_{2}$ atmosphere. The $\mathrm{N}, \mathrm{N}$-dimethylformamide (DMF) solvent was purged with $\mathrm{N}_{2}$ for 15 minutes before used. $\mathrm{NiCl}_{6} \cdot 6 \mathrm{H}_{2} \mathrm{O}(2.38 \mathrm{~g}, 0.01 \mathrm{~mol})$ and triphenylphosphine(10.37 g, 0.04 mol) were dissolved in a $150 \mathrm{~mL}$ DMF to yield a blue solution. $0.65 \mathrm{~g}$ of $\mathrm{Zn}$ powder $(0.01 \mathrm{~mol})$ was 
added into the mixture under nitrogen protection. The mixture was stirred for $1 \mathrm{~h}$ at $50{ }^{\circ} \mathrm{C}$ and then the methyl 4-bromo-2,6-difluorobenzoate $(2.51 \mathrm{~g}, 0.01 \mathrm{~mol})$ was added. The resulting mixture was further stirred for $10 \mathrm{~h}$ at $50{ }^{\circ} \mathrm{C}$ and cooled to room temperature. The methyl iodide $(2.50 \mathrm{~mL}, 0.04$ mol) was injected into the reaction mixture, which was further stirred for $1 \mathrm{~h}$ under room temperature. Finally, the resulting mixture was poured into distilled water to form grey-green precipitates. The solid precipitates were collected by suction filtration and washed with distilled water three times. The obtained solid precipitates were dissolved in ethyl acetate and the remaining solids were removed by filtration. The filtrate was condensed by rotatory evaporation yielded a solid. The solid was purified by a column chromatography with a eluent of dichloromethane/ $n$-hexane (1/2), yielding a white solid (1.03 g, 60.2\% based on methyl 4-bromo-2,6-difluorobenzoate). 1H NMR (400MHz, $\left.\mathrm{CDCl}_{3}, \mathrm{ppm}\right): \delta=3.94$ (s, 6H), $7.84(\mathrm{~s}, 2 \mathrm{H}), 7.87$ (s, 2H).

(2) Synthesis of 3,3',5',-tetrakis(fluoro)biphenyl-4,4' -dicarboxylic acid (b). Compound a (0.34 g, 1 mmol) was dissolved in a mixed solvent of $60 \mathrm{~mL} \mathrm{MeOH}$ and $60 \mathrm{~mL}$ THF in a $250 \mathrm{~mL}$ round bottom flask. $20 \mathrm{~mL}$ of $1 \mathrm{M}$ aqueous $\mathrm{NaOH}(20 \mathrm{mmol})$ was added to the former solution, and the resulting mixture was refluxed for $2 \mathrm{~d}$. Afterwards, the resulting mixture was cooled to room temperature and poured into distilled water $(60 \mathrm{~mL})$. The $\mathrm{pH}$ value of the mixture was adjusted to 2 by adding concentrated $\mathrm{HCl}$ to give a white precipitate, which was collected by suction filtration and washed by distilled water three times. Yield $0.26 \mathrm{~g}(81 \%)$. 1H NMR (400 MHz, DMSO- $\left.d_{6}, \mathrm{ppm}\right): \delta=7.72(\mathrm{~s}$, 2H), $7.75(\mathrm{~s}, 2 \mathrm{H}), 14.02(\mathrm{~s}, 2 \mathrm{H})$.

Physical Measurements. FT-IR spectrum was recorded from $\mathrm{KBr}$ disc on a Perkin-Elmer Spectrum One FT-IR spectrometer ranging from 400 to $4000 \mathrm{~cm}^{-1}$. Thermogravimetric analyses were performed under a nitrogen atmosphere with a heating rate of $10^{\circ} \mathrm{C} / \mathrm{min}$ using a PE Diamond thermogravimetric analyser. Powder X-ray diffraction analyses were performed on a Rigaku Miniflex 600 diffractometer with $\mathrm{Cu}-\mathrm{K} \alpha$ radiation $(\lambda=1.5418 \AA)$.

\section{Ideal adsorbed solution theory (IAST) calculations of adsorption selectivity and isosteric heat} of adsorption. The isosteric heat of adsorption, $Q_{\mathrm{st}}$, is defined as

$$
Q_{s t}=R T^{2}\left(\frac{\partial \ln p}{\partial T}\right)_{q}
$$


The $\mathrm{C}_{3} \mathrm{H}_{4}$ and $\mathrm{C}_{3} \mathrm{H}_{6}$ adsorption data were fitted using a Virial-type expression (Figure S6). ${ }^{1}$ Then the $Q_{\text {st }}$ values for $\mathrm{C}_{3} \mathrm{H}_{4}$ and $\mathrm{C}_{3} \mathrm{H}_{6}$ were calculated based on the fitting parameters with the above expression (Figure S7).

The IAST was used to predict mixed gas behavior from experimentally measured single-component isotherms. ${ }^{2}$ The experimentally measured loadings for $\mathrm{C}_{3} \mathrm{H}_{4}$ and $\mathrm{C}_{3} \mathrm{H}_{6}$ at $298 \mathrm{~K}$ in JXNU-6a were fitted with the single-site Langmuir isotherm model (Figure S9).

$$
q=q_{A, s a t} \frac{b_{A} p^{c_{A}}}{1+b_{A} p^{c_{A}}}
$$

Where $p$ (unit: $\mathrm{kPa}$ ) is the pressure of the bulk gas at equilibrium with the adsorbed phase, $q$ (unit: mmol $\mathrm{g}^{-1}$ ) is the adsorbed amount per mass of adsorbent, $q_{A \text {,sat }}$ (unit: $\mathrm{mmol}^{-1}$ ) is the saturation capacity, $b_{A}$ (unit: $1 / \mathrm{kPa}$ ) is the affinity coefficient. The $c_{\mathrm{A}}$ represents the deviation from an ideal homogeneous surface site.

The adsorption selectivity for binary mixture (A and B) using the Langmuir fitting parameters is defined by

$$
S_{a d s}=\frac{q_{A} / q_{B}}{y_{A} / y_{B}}
$$

(where the $q_{\mathrm{A}}$ and $q_{\mathrm{B}}$ represent the molar loadings $\left(\mathrm{mmol} \mathrm{g}^{-1}\right)$. The $y_{\mathrm{A}}$ and $y_{\mathrm{B}}\left(y_{\mathrm{B}}=1-y_{\mathrm{A}}\right)$ are the mole fractions in a bulk fluid mixture).

\section{Sample information in breakthrough experiment:}

Length of adsorption bed:

$$
\mathrm{L}=100 \mathrm{~mm}
$$

Inner diameter of adsorption bed:

$\varphi=4 \mathrm{~mm}$

Total flow:

$2 \mathrm{~mL} \mathrm{~min}^{-1}$

Temperature:

$298 \mathrm{~K}$

Total pressure:

$1 \mathrm{~atm}$

weight of MOF sample

$0.347 \mathrm{~g}$

Grand canonical Monte Carlo (GCMC) simulation and Density Functional Theory (DFT) Calculation. All the GCMC simulation was performed using the Materials Studio 5.5 package. The adsorption sites of $\mathrm{C}_{3} \mathrm{H}_{4}$ and $\mathrm{C}_{3} \mathrm{H}_{6}$ at $298 \mathrm{~K}$ were obtained from GCMC simulations through the 
fixed loading task in the Sorption module. The host framework and the guest molecules were both regarded as rigid. The simulation box consisted of eight unit cell and the Metropolis method based on the universal forcefield (UFF) was used. The $Q_{\mathrm{Eq}}$ derived charges and the ESP charges derived by DFT were employed to the host framework and guest atoms, respectively. The cutoff radius was chosen as $15.5 \AA$ for the Lennard-Jones (LJ) potential, and the equilibration steps and production steps were both set as $5 \times 10^{6}$. We first optimized the JXNU-6a structure using the DFT method with periodic boundary. The widely used generalized gradient approximation (GGA) with the Perdew-Burke-Ernzerhof (PBE) functional and the double numerical plus d-functions (DND) basis set were used. An accurate DFT Semi-core Pseudopots (DSPP) was employed for the metal atoms. For all the DFT calculations, the energy, gradient and displacement convergence criterions were set as $1 \times 10^{-5} \mathrm{Ha}, 2 \times 10^{-3} \AA$ and $5 \times 10^{-3} \AA$, respectively.
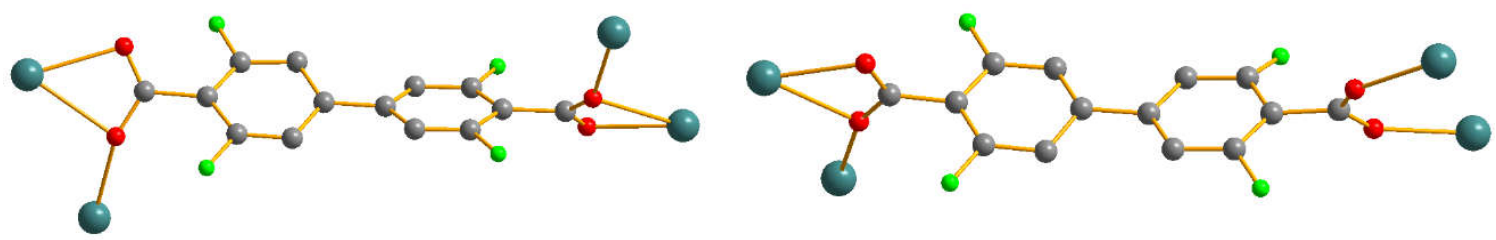

Figure S1. The coordination modes of the organic ligand in JXNU-6.

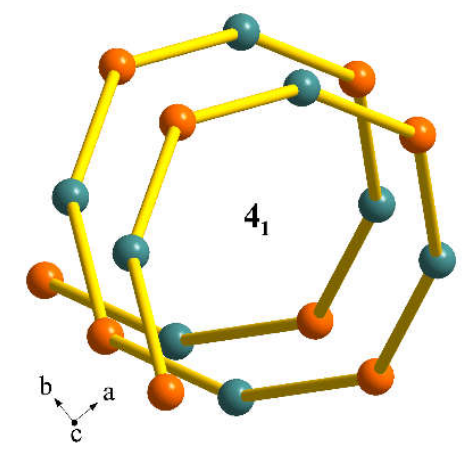

Figure S2. Schematic view of $4_{1}$ helix in $\mathbf{J X N U - 6}$ ( $\mathrm{The} \mathrm{Tb}(1)$ and $\mathrm{Tb}(2)$ atoms are represented with different colors). 


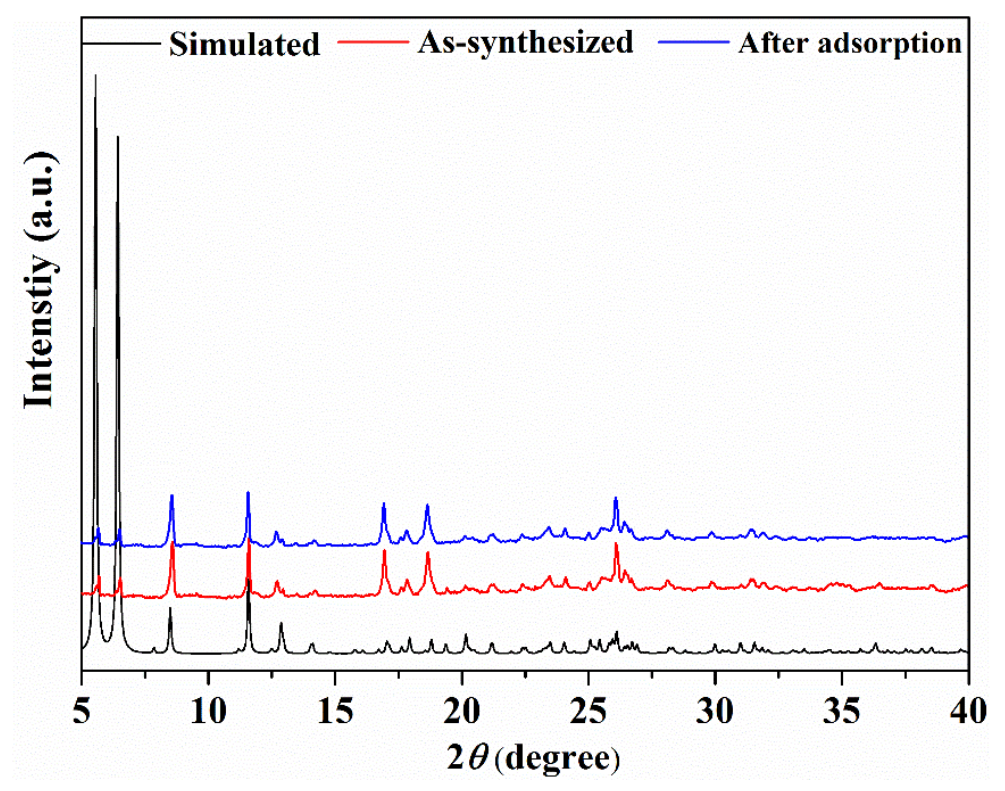

Figure S3. PXRD patterns for JXNU-6.

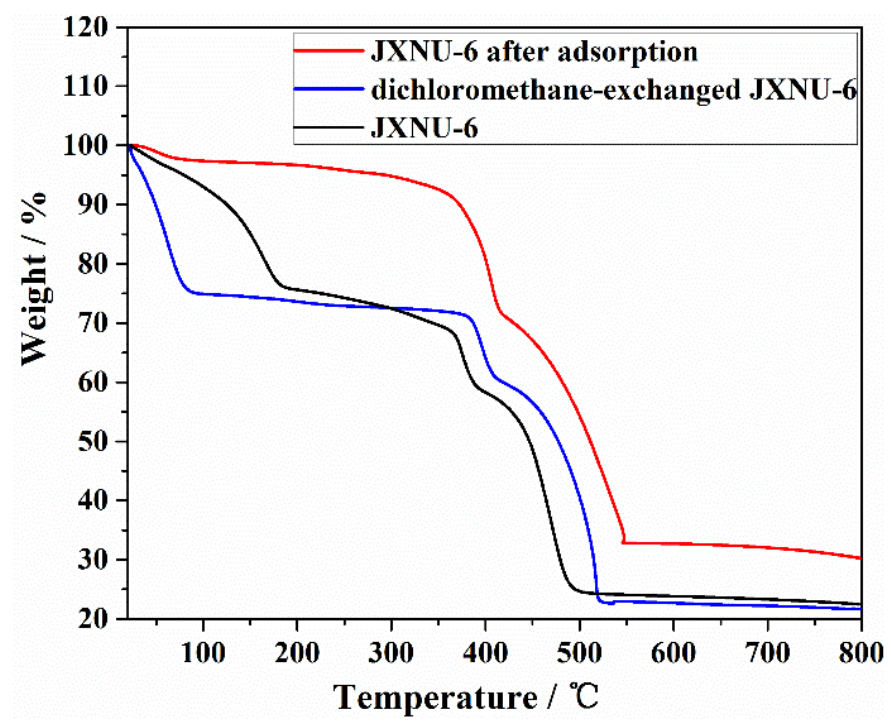

Figure S4. TGA curves. 

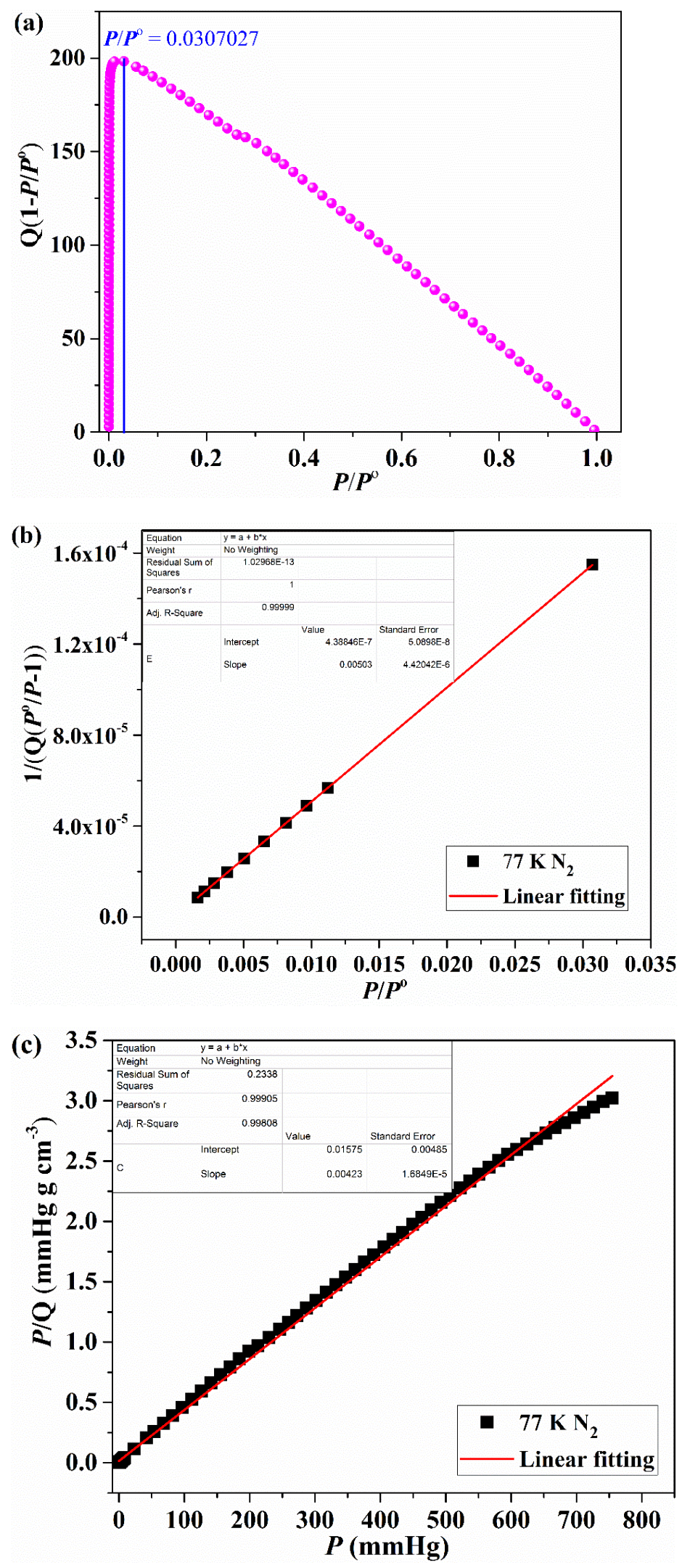

$$
\begin{aligned}
& S_{\mathrm{BET}}=1 /\left(4.38846 \times 10^{-7}+0.00503\right) / 22414 \times 6.023 \times 10^{23} \times 0.162 \times 10^{-18}=865.3 \mathrm{~m}^{2} \mathrm{~g}^{-1} \\
& S_{\text {Langmuir }}=(1 / 0.00423) / 22414 \times 6.023 \times 10^{23} \times 0.162 \times 10^{-18}=1029.1 \mathrm{~m}^{2} \mathrm{~g}^{-1}
\end{aligned}
$$

Figure S5. The consistency plot (a), BET surface area plot (b), and Langmuir surface area plot (c) for JXNU-6a. 

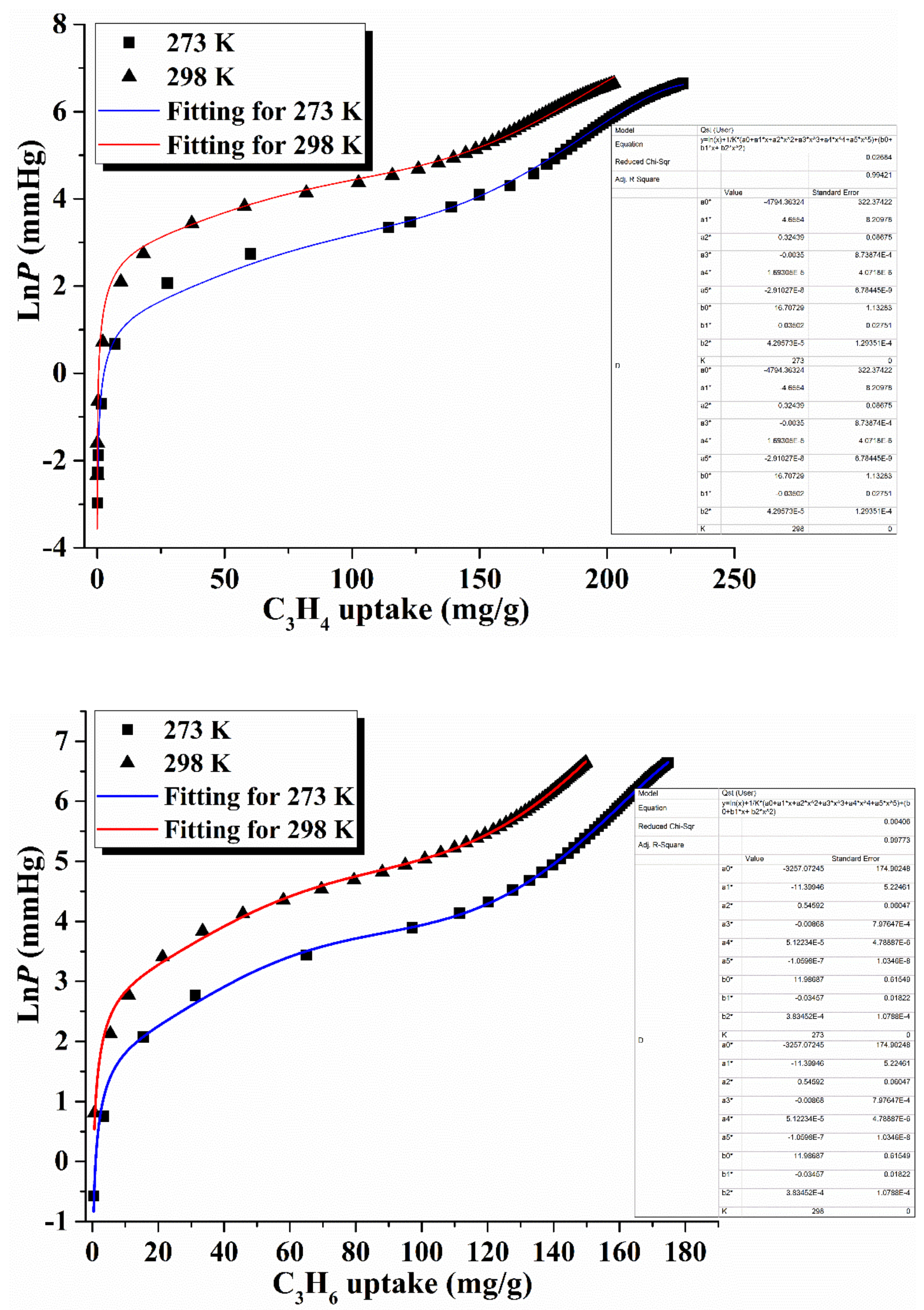

Figure S6. Virial fits of $\mathrm{C}_{3} \mathrm{H}_{4}$ and $\mathrm{C}_{3} \mathrm{H}_{6}$ isotherms for JXNU-6a. 


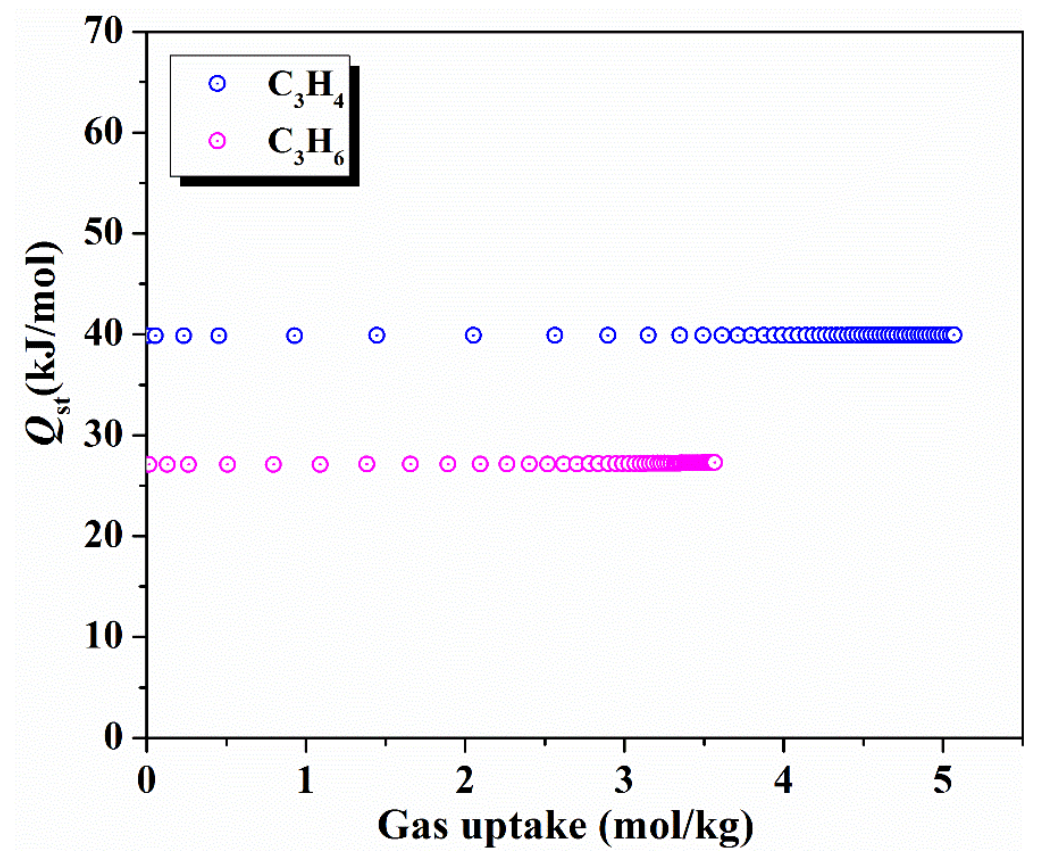

Figure S7. The $Q_{\mathrm{st}}$ of $\mathrm{C}_{3} \mathrm{H}_{4}$ and $\mathrm{C}_{3} \mathrm{H}_{6}$ adsorption for $\mathbf{J X N U - 6 a . ~}$

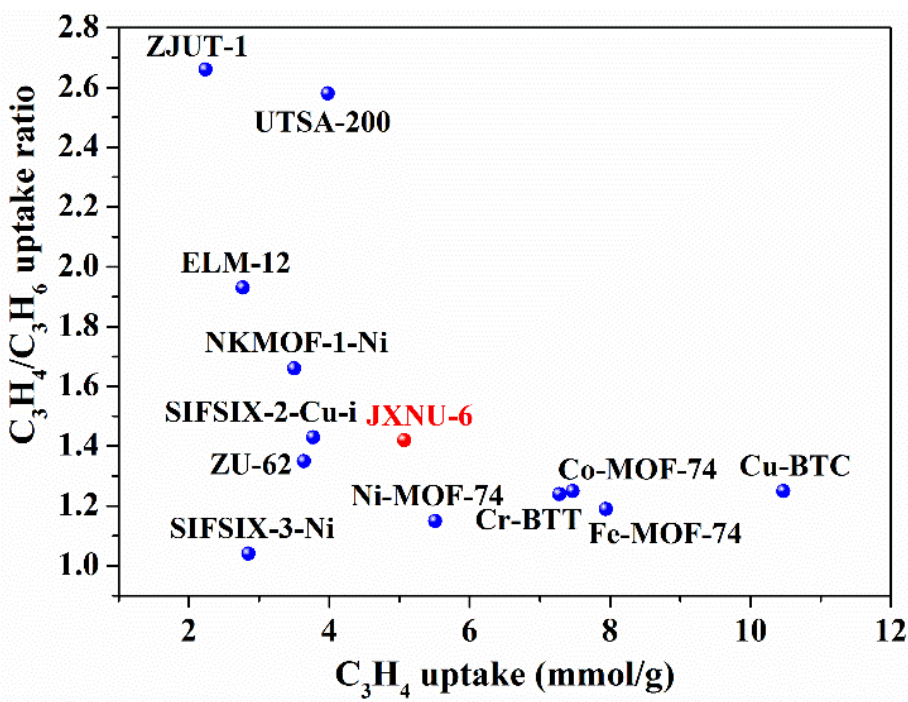

Figure S8. A comparison of $\mathrm{C}_{3} \mathrm{H}_{4} / \mathrm{C}_{3} \mathrm{H}_{6}$ uptake ratios at $100 \mathrm{kPa}$ and $298 \mathrm{~K}$ for $\mathbf{J X N U}-\mathbf{6 a}$ and other MOFs. 

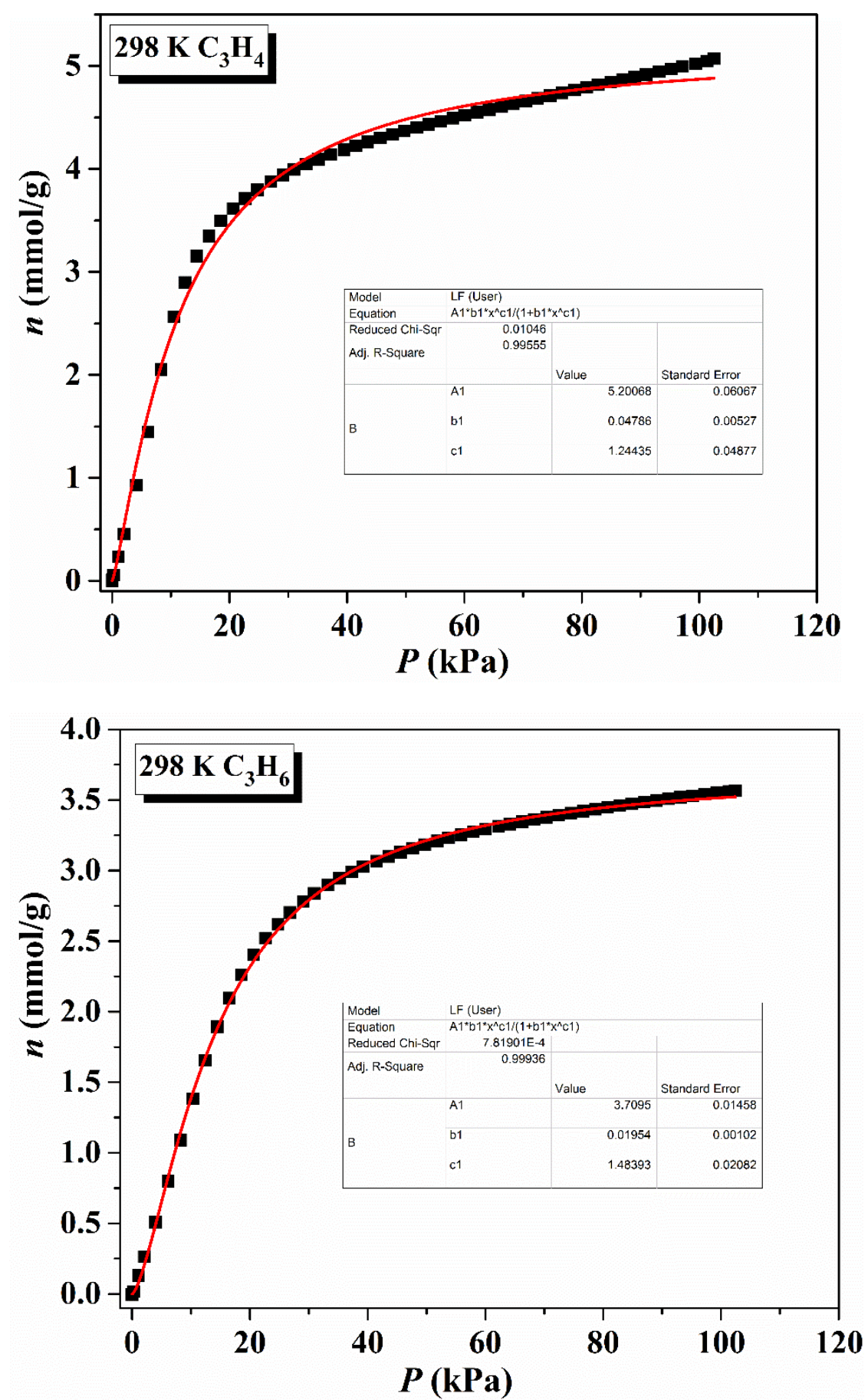

Figure S9. The graphs of the single-site Langmuir-Freundlich equation fit for adsorption of $\mathrm{C}_{3} \mathrm{H}_{4}$ and $\mathrm{C}_{3} \mathrm{H}_{6}$ on JXNU-6a at $298 \mathrm{~K}$. 


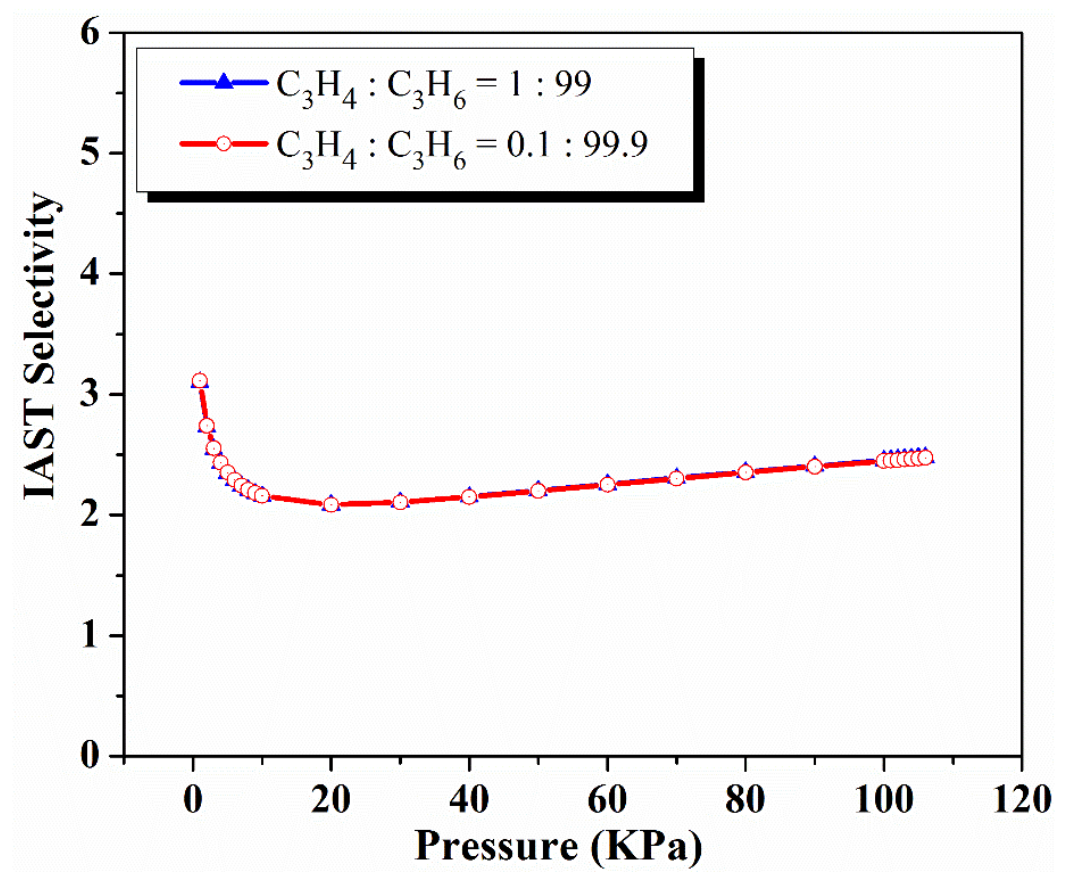

Figure S10. IAST calculations of adsorption selectivities for $\mathrm{C}_{3} \mathrm{H}_{4} / \mathrm{C}_{3} \mathrm{H}_{6}$ mixtures at $298 \mathrm{~K}$ for JXNU-6a.

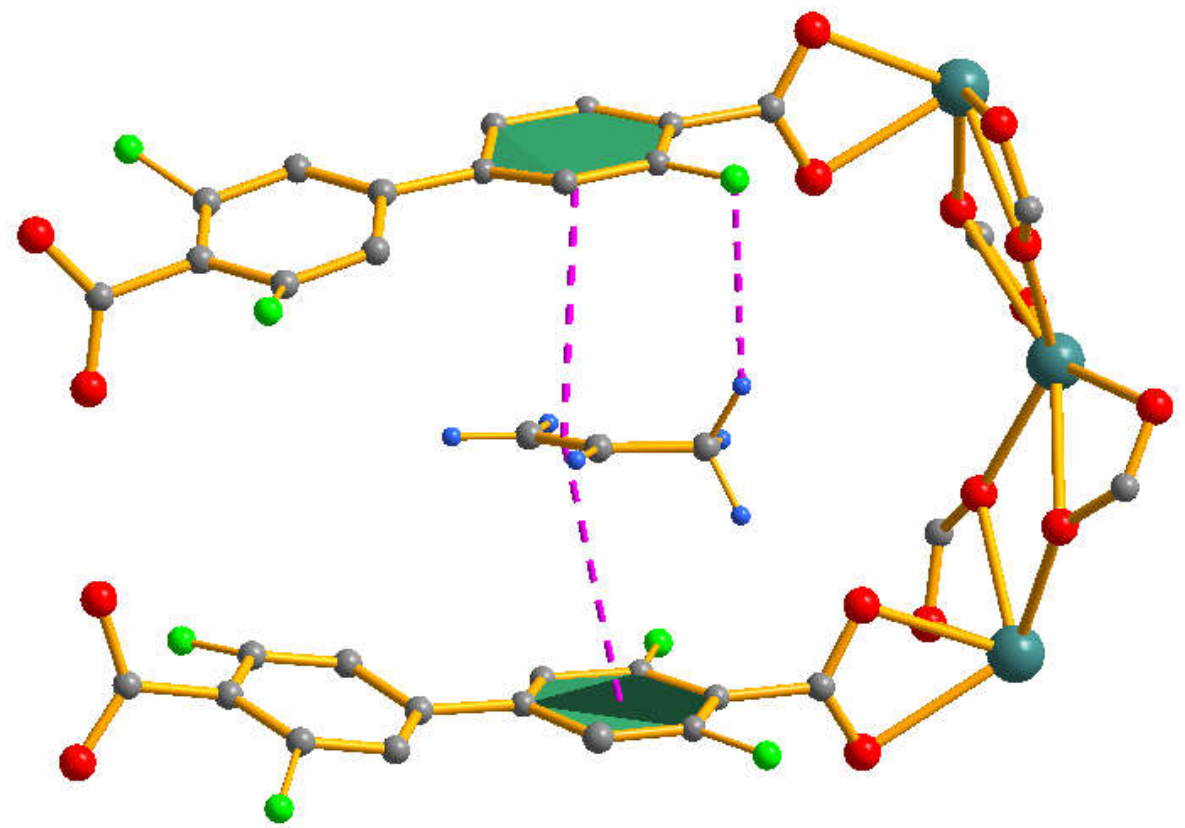

Figure S11. The preferential binding sites for $\mathrm{C}_{3} \mathrm{H}_{6}$ in JXNU-6a. 
Table S1. Selected Bond Lengths $(\AA)$ of JXNU-6.

\begin{tabular}{|c|c|c|c|}
\hline $\mathrm{Tb} 1-\mathrm{O} \mathrm{B}^{a}$ & $2.336(5)$ & $\mathrm{Tb} 2-\mathrm{O} 1$ & $2.326(5)$ \\
\hline $\mathrm{Tb} 1-\mathrm{O} 6 \mathrm{C}$ & $2.336(5)$ & $\mathrm{Tb} 2-\mathrm{O} 1 \mathrm{D}$ & $2.326(5)$ \\
\hline Tb1-O1W & $2.375(9)$ & $\mathrm{Tb} 2-\mathrm{O} 4$ & $2.436(5)$ \\
\hline $\mathrm{Tb} 1-\mathrm{O} 3$ & $2.401(5)$ & $\mathrm{Tb} 2-\mathrm{O} 4 \mathrm{D}$ & $2.436(5)$ \\
\hline $\mathrm{Tb} 1-\mathrm{O} 3 \mathrm{~A}$ & $2.401(5)$ & $\mathrm{Tb} 2-\mathrm{O} 3$ & $2.552(5)$ \\
\hline $\mathrm{Tb} 1-\mathrm{O} 2$ & $2.436(4)$ & $\mathrm{Tb} 2-\mathrm{O} 3 \mathrm{D}$ & $2.552(5)$ \\
\hline $\mathrm{Tb} 1-\mathrm{O} 2 \mathrm{~A}$ & $2.436(4)$ & $\mathrm{Tb} 2-\mathrm{O} 5 \mathrm{C}$ & $2.273(6)$ \\
\hline $\mathrm{Tb} 1-\mathrm{O} 1$ & $2.623(5)$ & $\mathrm{Tb} 2-\mathrm{O} 5 \mathrm{E}$ & $2.273(6)$ \\
\hline $\mathrm{Tb} 1-\mathrm{O} 1 \mathrm{~A}$ & $2.623(5)$ & & \\
\hline
\end{tabular}

\section{References}

(1) Rowsell, J. L. C.; Yaghi, O. M. Effects of Functionalization, Catenation, and Variation of the Metal Oxide and Organic Linking Units on the Low-Pressure Hydrogen Adsorption Properties of Metal-Organic Frameworks. J. Am. Chem. Soc. 2006, 128, 1304-1315.

(2) Myers, A.-L.; Prausnitz, J. M. Thermodynamics of mixed-gas adsorption. AIChE J. 1965, 11, $121-127$. 